\title{
The influence of load distribution in kinematic constraints of connecting rod on the results of the stress simulation
}

\begin{abstract}
The article presents the results of simulations research carried out, using Finite Element Method. The simulations were made in the Abaqus software. Calculations were made on the connecting rod of opposed piston engine. The connecting rod was subjected to a compression tests. Different versions of the boundary conditions in the form of load forces and pressure distribution acting on the small end of the connecting rod were presented. Depending on the load distribution acting on the connecting rod small end, different distributions of stresses in the connecting rod geometry were obtained. All studies were performed for the same geometry, the same mesh grid, and for the same value of compressive force (research could be considered as comparable). Changing the size and distribution of stresses in the connecting rod, evidence the impact of the adopted boundary conditions of the load distribution on the calculation results. It is important for the use of modern simulation tools in the design process of new mechanical parts.
\end{abstract}

Key words: connecting rod, simulation, FEM, Abaqus, Catia v5

\section{Introduction}

Within the research project realized with WSK "PZLKALISZ" S.A., the design of the aircraft engine with opposing pistons is being developed. This engine will be used in ultralight aircraft. This type of engine has many advantages:

- lower fuel consumption than other piston engines (better efficiency),

- reduced heat losses because of the small area of the combustion chamber (no engine head),

- leaner combustion (Diesel operation),

- faster and earlier combustion at the same pressure rise rate (large flame front surface),

- lower pollutant emission compared to turbine engines,

- lower costs (small number of parts and simple design).

At present, due to environmental requirements and dealing with climate change, it is beneficial to develop aircraft piston engines and adopt the achievements of automotive engineering such as computer controlled common rail high pressure injection systems and variable pressure turbochargers.

For this reason, modern simulation tools have been used to analyze the various design solutions used in such an engine. One good example are FEM analysis, which allows to estimate stress values in main engine components. This article focuses on the connecting rod stress calculations. It should be emphasized, that in order to obtain the simulated results as close as possible to reality, the conditions defined during the simulations have to be identical to the real ones. Sometimes it is impossible or difficult to estimate these conditions. In such a case, committing a non-major error in the initial calculation phase may result in erroneous results of the simulation calculations. Therefore, the authors of the article decided to examine the effect of boundary conditions of the connecting rod compression simulations on the obtained results of the simulation.

\section{Research simulations - introduction}

Strength tests of the connecting rod were made using Finite Element Method in the Abaqus software. This is a software commonly used for this type of analysis. The geometry of the connecting rod was taken from opposite piston engine. This model was designed by geometry changing, resulting from the previously performed optimization calculations. This article presents the target model, which was the 8 th analyzed model. The article identifies the same boundary conditions as in model previously described in [5].

From the studies conducted in [5], it was found that the results of the simulation tests of the tested model were strongly dependent to the load conditions that were applied to the connecting rod model. Despite the same conditions of restraint and the same values of forces acting on the model, the size and the distribution of stresses were influenced by the method of load distribution [6]. In addition, all the models used the same material data. It should be noted, that the connecting rods that are discussed where analyzed only for the compression, while the same differences have been observed for the connecting rod stretching simulations [6]. As a result of noticeable changes in stress distribution, it was decided to expand this discussion and perform several simulations with different load distributions for the connecting rod $[1,2,4]$.

\section{Load boundary conditions}

This section presents the variable boundary conditions for several analyzed models.

\subsection{Load 1 version}

In the first version, the boundary conditions were determined by giving a fixation at one point in the center of the connecting rod, where all degrees of freedom were fixed. The load was realized by connecting the first reference point to the lower surface of the rod bushing and connecting the second reference point to the top surface of the upper rod bearing insert. The compression forces acting in the vertical direction were applied to the reference points. This way of defining the load has resulted in the distribution shown in Figure 1. 


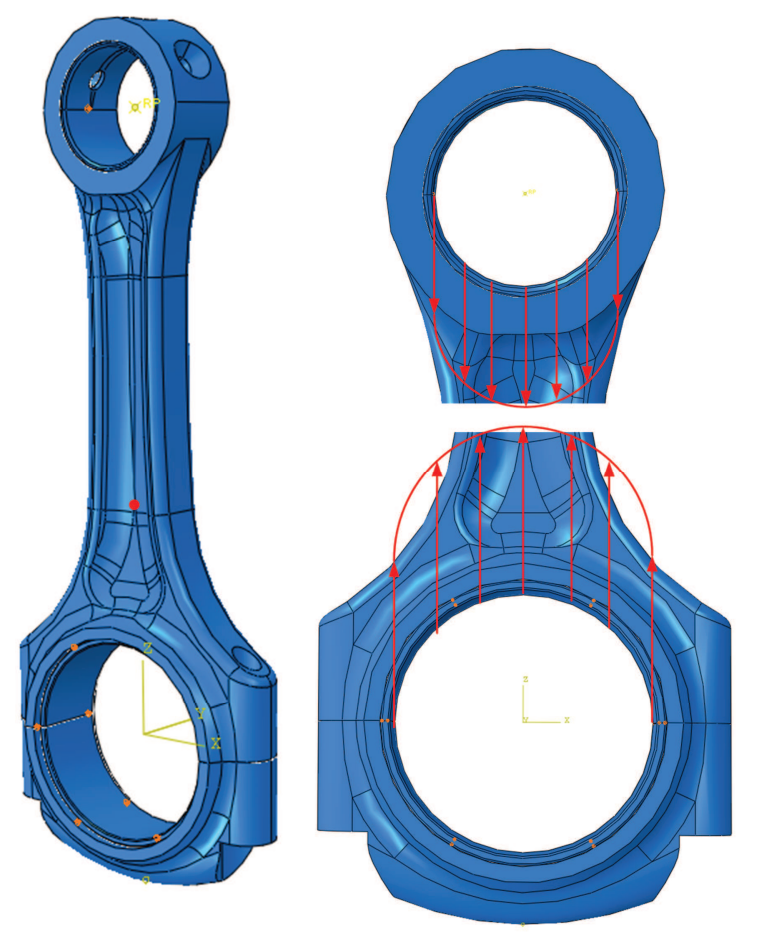

Fig. 1. Fix and load 1 version

\subsection{Load 2 version}

In the second version, the boundary conditions were determined by assigning a fixation at one point of the center of the connecting rod, where all degrees of freedom were fixed. The load was realized by defining the pressures identical to the forces values from version 1. Those pressures were applied perpendicularly to the bottom surface of the rod bushing and the top surface of the upper rod bearing insert. This way of defining the load has resulted in the distribution shown in Figure 2.

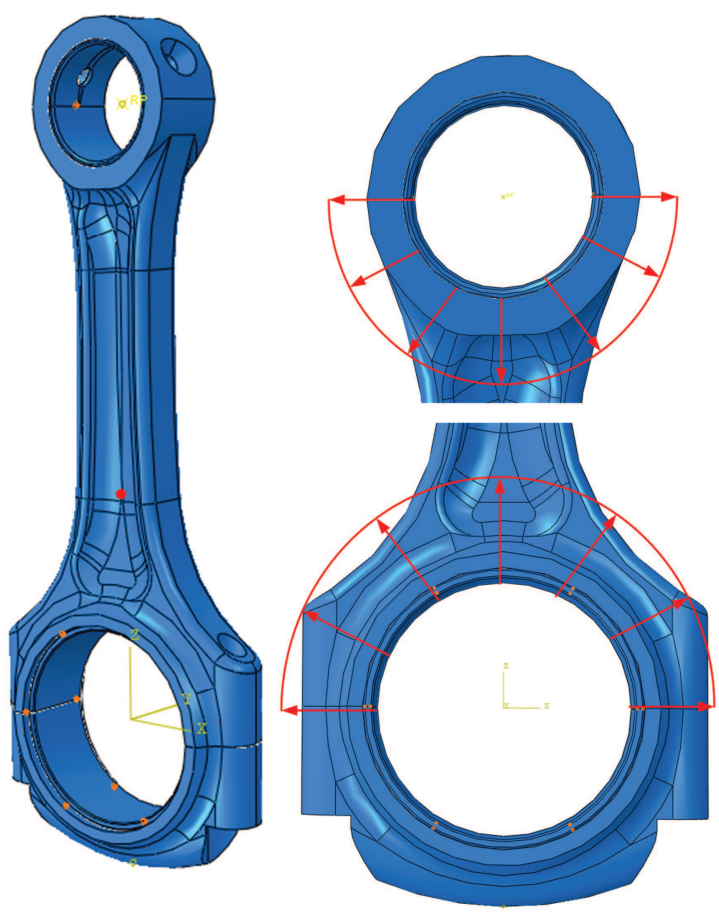

Fig. 2. Fix and load 2 version

\subsection{Load 3 version}

In the third version, the boundary conditions were determined by assigning only one center point of the connecting rod, where all degrees of freedom were fixed. However, the load was realized by defining pressure on two surfaces. On the bottom surface of the rod bushing and on the top surface of the upper rod bearing insert. The load values were identical to the force from version 1 and 2 . The pressure was defined by the distribution of pressure from the sinusoidal function depending on the length of the arc. This way of the load defining has resulted in the distribution shown in Figure 3.

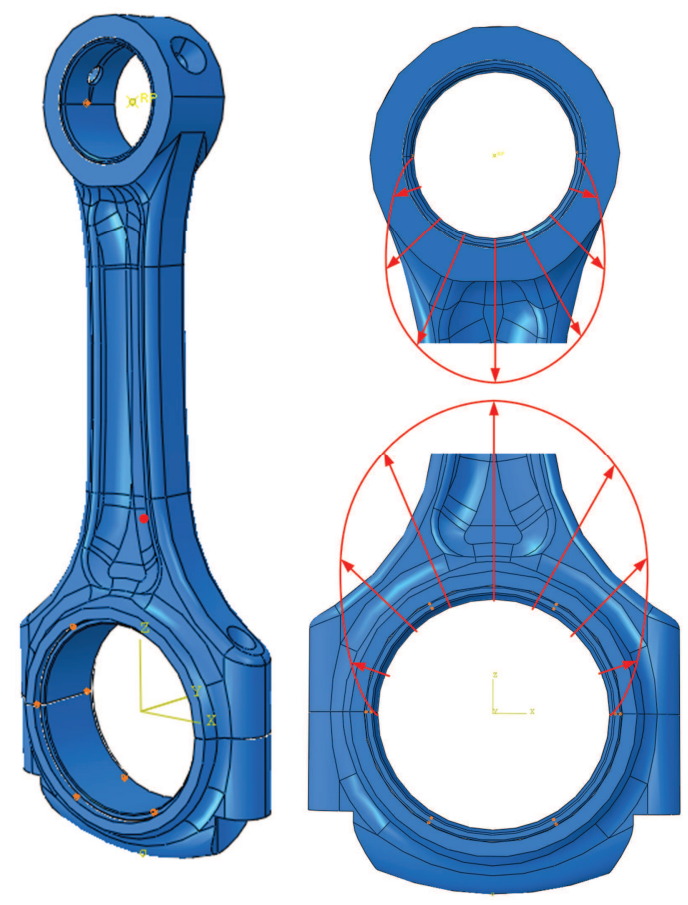

Fig. 3. Fix and load 3 version

In this version of the calculations, it was decided to determine the pressure distribution on the rod bushing (connecting small end) and the upper rod bearing insert (connecting rod big end) depending on the coordinate $\mathrm{x}$. The pressure distribution was based on the force acting on these surfaces. It was decided to use the function determining the most real pressure distribution in case of sliding contact.

$$
\mathrm{p}=\frac{\mathrm{F}}{\mathrm{a} \cdot \mathrm{b}} \cos \left(\mathrm{a} \sin \left(\frac{\mathrm{x}}{\mathrm{y}}\right)\right)
$$

where: $\mathrm{p}$ - pressure, $\mathrm{F}$ - force, $\mathrm{a}, \mathrm{b}$ - width and length of the surface projection of the surface of the rod bushing/upper rod bearing insert on the transverse plane to the main axis of the connecting rod, $\mathrm{x}$ - distance value perpendicular to the main axis of the connecting rod, $r$ - inner rod bushing/upper rod bearing insert radius.

The graph of the above function is presented in Figure 4. The horizontal axis shows the dimension in [mm] corresponding to the length of the surface projection of the surface of the rod bushing on the transverse plane to the main axis of the connecting rod, while the vertical axis represents the dimensionless pressure value for which 1 corresponds 
to the maximum pressure value. The function was chosen in such a way, that the sum of the vertices values of the pressure (acting along the connecting rod main axis) was identical to the same values in versions 1 and 2 .

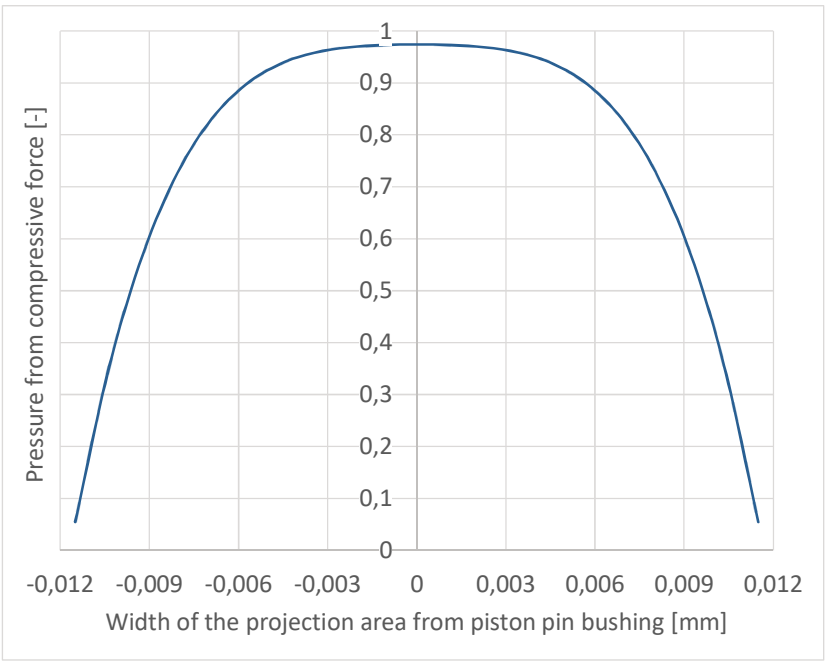

Fig. 4. Function graph describing the pressure distribution on the surface of the rod bushing

\section{Simulation research}

This part of the paper presents the results of the simulation tests for all three versions of the connecting rod loads.
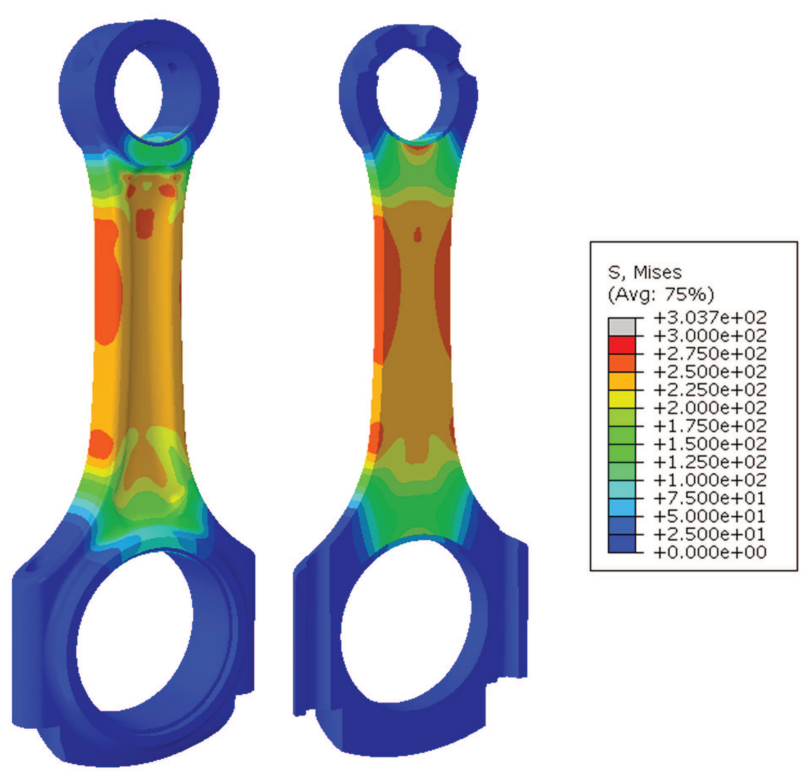

Fig. 5. Results of simulation tests, connecting rod compression 1 version

In the case of version 1 , the maximum stresses values are the smallest. Also their range on the rod small end and big end are the smallest (blue color). The highest stresses values are in version 2 ( 3 times bigger). This is due to the fact that in case 1 , there is only vertical component of the compression force. In other cases also horizontal components of forces occurs, of which in the second version they are the largest. This causes additional bending of the connecting rod small end to the outside. The loads in case 3 are most similar to the real distribution because the force applied decreases to 0 for a distance equal to the radius of the rod bushing, measured from the main axis of the connecting rod. In this case, the maximum stresses are slightly higher than in version 1 . The location of the areas with the highest stress values are different. In case 1, they occur near the rod small end and big end, which results from the tensile force acting sideways.
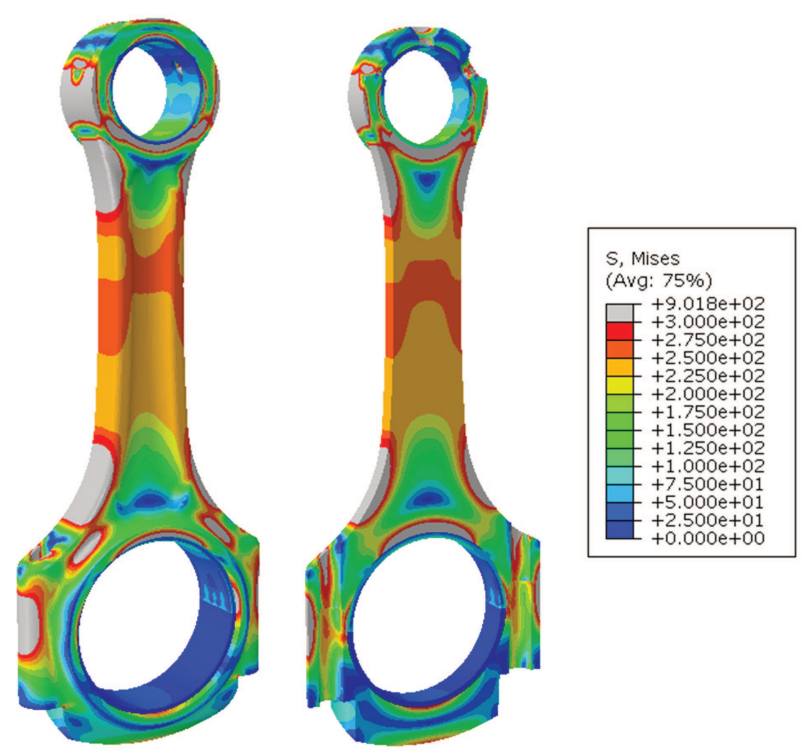

Fig. 6. Results of simulation tests, connecting rod compression 2 version
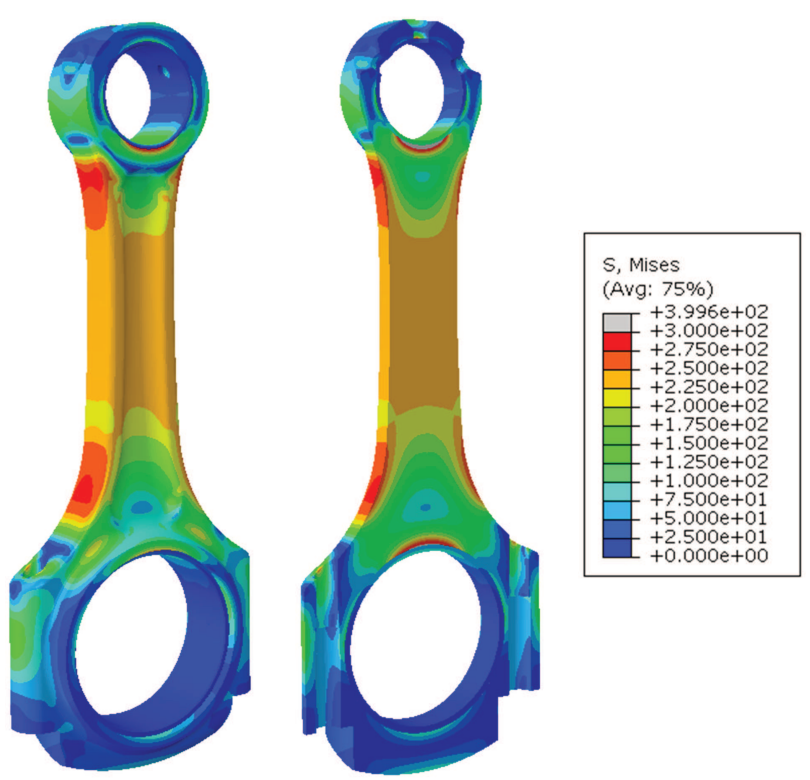

Fig. 7. Results of simulation tests, connecting rod compression 3 version

\section{Summary}

FEM modeling allows to get quick results without having to carry out costly and laborious occupational testing. However, depending on the degree of simplification of the boundary conditions, the results may vary in small or to a large extent from reality. In the case of connecting rod stress calculations, it is therefore essential to correctly define the distribution of applied forces or pressures. The calculation results show that the maximum stresses can be 3 times greater than the real ones, which can lead to overdimensioning of the element. 
The closest to the real distribution of forces is presented in the version 3. However, the determination of such case is a little difficult, because it is necessary to apply pressure rather than direct force to the model. In the case of version 1 , the results do not differ significantly from case 3 . It is therefore not a great mistake to assume such a force distribution, which is a common practice. However, it is not possible to assume boundary condition presented in case 2 , as they are not identical with the actual load distribution and result in a false values.

\section{Acknowledgement}

This work has been realized in the cooperation with The Construction Office of WSK "PZL-KALISZ" S.A." and is part of Grant Agreement No. POIR.01.02.00-00-0002/15 financed by the Polish National Centre for Research and Development.

\section{Nomenclature}

FEM finite element method

\section{Bibliography}

[1] ABBEY, T. Understanding Load Paths, www.digitaleng.news/ de/understanding-load-paths/

[2] DASSAULT SYSTEMES, ELFINI Structural, Analysis CATIA V5 Training Exercises Version 5 Release 19, 2009.

[3] ZHUA, J.-C., ZHUA, H.-H., FANA, S.-D. et al. A study on the influence of oil film lubrication to the strength of engine connecting rod components, Engineering Failure Analysis. 2016, 63, 94-105.

[4] KURDI, O., MAT NORMAN, M.A.B., YULIANTI, I., MD RASHID, M.N.B. Simulation of fatigue life prediction and

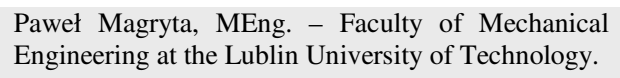

Michał Biały, MEng. - Faculty of Mechanical Engineering at the Lublin University of Technology.

e-mail:M.Bialy@pollub.pl
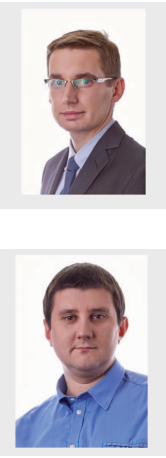

enhancement of connecting rod of car engine. Advanced Materials Research. 2012, 557-559, 2410-2414.

[5] MAGRYTA, P., PIETRYKOWSKI, K., MAJCZAK, A. Optimizing the geometry of the connecting rod in opposite pistons engine. Combustion Engines. 2017, 168(1), 191-196.

[6] TIWARI, A., TIWARI, J.K., CHANDRAKAR, S.K. Fatigue, analysis of connecting rod using finite element analysis to explore weight and cost reduction opportunities for a production of forged steel connecting rod. International Journal of Advanced Mechanical Engineering. 2014, 4(7), 782-802.

Konrad Pietrykowski, DEng. - Faculty of Mechanical Engineering at the Lublin University of Techno$\log y$.

e-mail: K.Pietrykowski@pollub.pl

Marcin Szlachetka, DEng. - Faculty of Mechanical Engineering at the Lublin University of Technology.

e-mail:M.Szlachetka@pollub.pl 